\title{
Power Struggles in the Implementation of Gender Equality Policies: The Politics of Resistance and Counter-resistance in Universities
}

Rebecca Tildesley

Universidad Complutense de Madrid

Emanuela Lombardo

Universidad Complutense de Madrid

Tània Verge

Universitat Pompeu Fabra

This article develops an analytical framework to study the power struggles between status quo and gender equality actors underpinning the implementation of gender equality

Research for this article was funded by the State Research Agency of the Spanish Ministry of Research through the UNiGUAL Project "Gender Equality Policies in Spanish University" (Ref: Fem201786004-R 10.13039/5011000110033). We also wish to thank the interviews' informants for sharing their time and knowledge with us, anonymous reviewers for their helpful comments, editors for their guidance, and the UNiGUAL team members, especially Alba Alonso, for commenting on a previous draft of this article. Rebecca Tildesley thanks the Spanish Ministry of Science, Innovation and Universities for funding her PhD scholarship, a predoctoral grant for the training of research personnel from the Promotion of Talent and Employability State Subprogram (Ref: PRE2018-084960).

(c) The Author(s), 2021. Published by Cambridge University Press on behalf of the Women, Gender, and Politics Research Section of the American Political Science Association. This is an Open Access article, distributed under the terms of the Creative Commons Attribution-NonCommercial-NoDerivatives licence (http://creativecommons.org/ licenses/by-nc-nd/4.0/), which permits non-commercial re-use, distribution, and reproduction in any medium, provided the original work is unaltered and is properly cited. The written permission of Cambridge University Press must be obtained for commercial re-use or in order to create aderivative work. 
policies. While resistance to gender equality policies in different institutions has received considerable scholarly attention, examining this struggle in light of a multifaceted concept of power that encompasses both domination and individual and collective empowerment, we argue, offers a more accurate account of the possibilities of a feminist politics of implementation. Our analytical framework also accounts for the factors that enable resistance by dominant actors and counter-resistance by gender equality actors and the informal rules that are being upheld or challenged, respectively. Applying our framework to the study of Spanish universities, we identify both the forms and types of resistance that hinder gender reform efforts in higher education institutions and the counter-action strategies that seek to drive implementation forward and achieve institutional change.

Keywords: Gender equality policy, implementation, power, resistances, counter-resistances, universities, feminist policy studies, feminist institutionalism

7 he implementation of gender equality policies is the result of a power 1 game between resistance and counter-resistance (Roggeband 2018). Whereas institutions can be challenged, negotiated, and subverted by gender equality actors, reform efforts often contend with ongoing opposition (Verloo 2018; Waylen 2014). This calls, on the one hand, for a thorough examination of the resistance that gender equality policies face during implementation (Engeli and Mazur 2018; Mergaert and Lombardo 2014; Verge and Lombardo 2021) - that is, efforts aimed at maintaining the status quo and opposing change (Lombardo and Mergaert 2013, 299). On the other hand, further research is needed to assess how gender equality actors seek to counteract resistance and push for feminist institutional transformation (Chappell and Mackay 2020; Eschle and Maiguashca 2018; Eyben 2010). While the concept of power is crucial for feminist institutionalist and feminist policy scholars, few existing analytical frameworks integrate it (exceptions include Celis and Lovenduski 2018; Lombardo and Meier 2009; Verge and de la Fuente 2014).

Taking stock of and contributing to these two strands of literature, this article develops an analytical framework to conceptualize and empirically examine the power struggles underpinning implementation processes, the most understudied policy stage (Engeli and Mazur 2018). We argue that the oppositional, interactive dynamics of politicization between resisting actors and gender equality actors call for the adoption of a multifaceted feminist concept of power (Allen 1998) that encompasses both domination (power over) as well as individual (power to) and collective (power with) counter-resistance. This analytical framework allows for a more accurate account of the constraints imposed 
on actors carrying out gender equality work and the possibilities of a feminist politics of implementation.

We apply our framework to the study of five Spanish universities. Spain is an illustrative case of policy failure in which formal higher education gender equality rules have experienced ongoing contestation and poor implementation. In examining power over, understood as the domination exercised at the individual or group level that serves to disadvantage others and maintain the unequal status quo, we identify the forms and types of resistance that constrain the choices and strategies available to gender equality actors in a routinized way, while unveiling the underlying informal gendered rules and enabling factors. In the case of counter-resistance, we study both power to, which refers to the strategies deployed individually by gender equality actors to empower themselves and steer policy implementation, and power with, the collective strategies and alliances that these actors form to subvert gendered domination and achieve institutional change. In doing so, we identify the informal rules that gender equality actors seek to subvert and the factors that enhance their capacity to act.

Drawing on face-to-face interviews with key actors involved in the implementation of universities' gender equality policies, our empirical analysis shows that while resistance hinders their effective implementation, gender equality actors seize and shape the political opportunity structure to their advantage to transform the institutions they engage with. The remainder of the article is structured as follows: The first section develops our analytical framework for investigating gender power struggles. The second section presents the data and methods used. The next two sections outline how power over, on the one hand, and power to and power with, on the other, are deployed in higher education institutions. The last section discusses the implications of our findings for the study of feminist policy implementation.

\section{GENDER POWER STRUGGLES IN IMPLEMENTATION PROCESSES: A FRAMEWORK FOR ANALYSIS}

Policy implementation involves conflict and negotiation between multiple actors with different interests that pursue a series of individual and collective strategies to either hinder or support implementation (Bardach 1977). Gender equality policy implementation processes are especially complex (Engeli and Mazur 2018) as they are resisted by dominant or 
privileged actors that seek to maintain the status quo from which they benefit (Verloo 2018). Power struggles between status quo and feminist actors in charge of gender equality reforms are thus intrinsic to implementation (Roggeband 2018). As Celis and Lovenduski (2018, 153) remark, "the concept of power struggle(s) captures both feminist strategies and actions, and the resistances they encounter." These codependent dynamics, we argue, involve those actors that resist gender equality policies and the changes they imply, and those actors that deploy counter-resistance to actively promote or sustain policy implementation. By analyzing both the resistances that seek to maintain the status quo and the counter-resistances deployed to counteract obstructing forces and drive change, our analytical framework addresses the scholarly gap of bringing power struggles to the forefront of analyses of gender equality policy implementation.

In university settings, while feminist academics and research groups were historically the main actors striving for gender reforms, equality units have become the main drivers of policy change, particularly, although not exclusively, in Europe. These specialized bodies, similar to what diversity units do for promoting race and disability equality in universities (Ahmed 2012), are tasked with steering the implementation of multiyear gender action plans and advising university bodies on how to mainstream gender in all policies. Equality units tend to be led by feminist scholars appointed by the university rector, the chief executive authority of the institution (Pastor et al. 2015; Verge 2021). The equality structure also often includes an equality commission, with a deliberative and agendasetting role, made up of representatives from the student body and administrative and faculty staff.

Identifying the actors that resist gender equality policy implementation is less straightforward. Resistance can be deployed by administrative or faculty staff, students, top managers, or members of the governing team, motivated by competition for resources or anti-feminist, conservative, or apparently gender-neutral ideologies (La Barbera and Lombardo 2019). It may also come from well-intentioned allies that nevertheless cause tensions or "friendly fire," as found in other arenas (Roggeband 2018, 31). The distinction between individual and institutional resistance is also fuzzy. When resistance comes from individuals occupying top decision-making positions, their decisions and actions are likely to lead to institutional inertia toward the status quo. Simultaneously, decisions regarding institutional priorities and the allocation of resources may trigger "unintended" individual resistance. For example, failure to provide staff 
with gender training is likely to leave them ill equipped to implement gender mainstreaming in their daily tasks (Lombardo and Mergaert 2013, 301).

Expressions of power over, the actions (or non-actions) that have the capacity to undermine the implementation of gender equality policies, "constrain the choices available to another actor or set of actors in a nontrivial way" (Allen 1998, 33). Consequently, the capacity of gender equality actors to drive their reform agendas is curtailed. Furthermore, in their effort to maintain the status quo, opposing actors contribute to the reproduction of the institution's gender regime, perpetuating the dynamics, hierarchies, and patterns of discrimination embedded within the organizational culture that reward masculinity and disadvantage women (Chappell 2006). Characterizing universities as institutional contexts riddled with gender power dynamics allows us to identify a wide range of practices that sustain androcentric approaches to teaching and research, devalue "institutional housekeeping" and relational work, and maintain men's overrepresentation in the higher echelons of academia and decision-making (Monroe et al. 2008; Valian 2004). More generally, university policies continue to build on representations of disembodied, genderless students, teachers, and managers, infused by an ethos of presumed objectivity and meritocracy (Benschop and Brouns 2003).

Resistance adopts a variety of forms, such as the denial of the need for gender change, the refusal to take responsibility, and the trivialization of the importance of equality policies or gender equality for the institution's work (Mergaert and Lombardo 2014; Verge, Ferrer-Fons, and González 2018). It may be expressed explicitly or implicitly (Lombardo and Mergaert 2013), constituting more or less visible manifestations of power over. Explicit, visible resistance unfolds through individual discourses or institutional decisions that directly undermine policies or contradict legal mandates, such as opposition to positive actions. Implicit resistance through non-action or limited action on issues that do not benefit the interests or values of dominant actors (Lukes 2005), such as the failure to allocate (sufficient) resources, may also jeopardize or delay implementation processes. "Power," argues Lukes $(2005,1)$, "is at its most effective when least observable," when inequalities are naturalized in daily institutional life, becoming "nonproblems." The denial of the need to address gender inequalities grounded in gender biases, perceptions of male entitlement to academic privilege, or the undervaluation of women's academic work are examples 
of implicit, invisible resistance that legitimizes and institutionalizes men's domination and women's subordination.

These manifestations of power tend to be entrenched in a web of both gendered and apparently gender-neutral formal (written) and informal (nonwritten) rules - that is, values, norms, routines, and practices that constitute the "rules of the game" of an institution (Chappell and Waylen 2013; Mackay, Kenny, and Chappell 2010). Rules are "gendered" when roles, actions, or benefits are marked by social scripts around masculinity and femininity, including gender stereotypes, role expectations, or prejudice against feminist policy. They might be "apparently gender-neutral" but nonetheless yield "gendered effects" because of their interaction with wider social norms (Lowndes 2020). Examples in academia include intensive-work dedication that neglects the sexual division of labor and individual merit that informs disembodied university practices and processes (Verge, Ferrer-Fons, and González 2018, 96). ${ }^{1}$ Resistance is more likely to arise when reforms target or contradict the hegemonic values and norms of an organization (Benschop and Verloo 2006; Mergaert and Lombardo 2014, 15), as is the case of the policies aimed at gendering universities.

To address the question of how resistance is countered, we must turn to the other two sides of power, which are concerned with empowerment rather than domination (Allen 1998, 32). First, power to is defined as "the capacity of an agent to act in spite of, or in response to, the power wielded over her by others" (Allen 1998, 34). Generally lacking positional power, gender equality actors may seek a balance between explicit, more confrontational strategies and subtler, behind-the-scenes ones. Because of their less visible character, the latter may be easier to deploy even if they require "infusing' gender into existing ways of doing and organizing things" (Eyben 2010, 55). This includes disguising transformative agendas in hegemonic institutional logics, by either adopting ordinary institutional politics or strategically employing mainstream discourses to their advantage (Eyben 2010; Hart 2008). Efforts toward gendering quality assurance discourses in universities are an example (Morley 2007; Verge 2021).

1. The absence of measures that take into account or compensate for the setback in research productivity provoked by the COVID-19 global pandemic, particularly for women academics, who assume the bulk of the extra care work resulting from the closure of nurseries, schools, and day centers for the elderly, is another dramatic example of gender-blind rules exacerbating gender inequalities. 
Gender equality actors may also seek the accumulation of "small wins" (Chappell and Mackay 2020; Weick 1984), taking advantage of political opportunities that arise within or outside the university. Indeed, "tempered radicalism" might avoid the resistance that bigger projects provoke (Meyerson and Scully 1995). Considering that equality units are typically understaffed, underbudgeted, and peripheral within the university structure (Elizondo, Novo, and Silvestre 2010; Pastor et al. 2015), low-risk, low-visibility strategies may be favorable. Simultaneously, "local, spontaneous, authentic action" may be practiced by gender equality actors to foster a climate conducive to effective implementation (Meyerson and Scully 1995, 596), carrying out daily acts of feminist activism, for example, in distinct academic spaces (Bendl et al. 2014; Mackay 2020). "Bridging" strategies with other actors, inside or outside the university, can afford gender equality actors an enhanced capacity to counteract resistance and drive implementation forward (Meyerson and Scully 1995, 597), providing them greater legitimacy and serving as important sources of information, support and lobby (Verge 2021). The "embeddedness" of the lead change actor in multiple environments and her legitimacy within the institution are likely to bolster her capacity to effect change, enhancing both credibility and leverage (Meyerson and Tompkins 2007, 318).

Second, gender equality actors might articulate collective strategies and alliances, deploying power with - the "ability of a collective to act together for the attainment of a common or shared, or series, of ends" (Allen 1998, 35). Concerted agency in actor "triangles," "coalitions," or "constellations" may compensate for a lack of individual positional and discursive power (Holli 2008; Woodward 2003). This strategy might include involving "feminist critical friends" - external researchers that share change agents' goals - in the design or implementation of equality work (Chappell and Mackay 2020). Change actors may also seek to expand opportunities for change through the creation or transformation of existing "scalar structures" - the multiplicity of levels and venues in which empowerment and mobilization strategies can be pursued (MacKinnon 2010). New institutional spaces or structures can bring together fresh constellations of change actors and enhance their collective capacity for action (Brenner 2001), even if these constitute "soft spaces" with fuzzy boundaries and pragmatic agendas (Allmendinger and Haughton 2009).

While formal or informal networks and spaces, particularly when they are made up exclusively of women, allow activists in the "margins" to organize, influence, and provide support for gender policy change 
within institutions (Chappell and Mackay 2017, 35), interinstitutional networks may also be important for mobilizing resources and garnering support for organizational change agendas (Eyben 2010). This might include interuniversity forums, networks of universities' equality units (Verge 2021), or research-funded projects to promote gender equality policies in university consortiums. ${ }^{2}$ Although gender equality actors are predominantly but not exclusively (feminist) women, and status quo actors are predominantly but not exclusively (privileged) men (Celis and Lovenduski 2018, 153), by not predefining the composition of the alliances or coalitions producing power with, we may identify male allies or unexpected gender-friendly actors in top positions of the organization (Holli 2008, 170; see also Childs and Krook 2009), externally, or in other parts of the university structure.

\section{CONTEXT AND METHODS}

The analysis of the power struggles between status quo and gender equality actors underpinning implementation processes focuses on Spanish higher education institutions. It constitutes an intriguing case because of the mismatch between the laws and policies in place and the slow pace of change toward gender equality in universities. As found elsewhere, Spanish higher education institutions are not alien to the increasing adoption of market principles that constrain a more egalitarian gender distribution of power, including new managerial approaches, the adoption of targets, benchmarking and quality assurance processes, or the merging of faculties on efficiency grounds (Castaño, VázquezCupeiro, and Martínez-Cantos 2019). Marketization, though, has not affected the election of governing teams in public universities. As required by law, the rector must be a full professor and elected through direct suffrage by the academic community. The rector then appoints the vice rectors from among the doctors rendering their service in the university, and the managers from among the civil servants. Faculty deans and school directors are also elected through direct suffrage.

The neoliberalization trend coexists with a binding regulatory framework on gender equality. In 2007, the Law on Universities (Act 4/2007) established the creation of dedicated gender equality structures for public

2. For a list of projects funded by the European Commission in the past few years to further the adoption and implementation of gender equality policies in higher education institutions and research centers, search "gender equality in higher education and research" at https://cordis.europa. eu/projects/en . 
universities. Both this law and the Law on Science and Technology (Act 14/2011) instruct universities to achieve gender balance in all collegial decision-making bodies, to promote women's greater participation as researchers, and to mainstream gender in research and teaching. For its part, the Equality Law (Act 3/2007) mandated the adoption of multiyear gender action plans by all public administrations. These plans, which must be negotiated with the staff and approved by the highest decisionmaking body of the university, must include actions that address inequality in the following domains at the very least: personnel policy, work-life balance measures, representation in decision-making positions, sexual harassment, gender-sensitive communications policy, and organizational culture. Universities' gender action plans have also incorporated actions for mainstreaming gender into teaching and research. Regional-level equality and university laws complement this countrywide framework.

Nonetheless, research has pointed to the slow and uneven institutionalization of university equality structures, poor implementation and monitoring of gender action plans, and the absence of positive action measures (Pastor et al. 2020). As a result, gendered horizontal segregation persists in study and research fields, and women remain underrepresented within the higher echelons of academia and in management and governing positions (Puy 2018, 19). Curricula remain fundamentally gender-blind, and few research groups tackle gender or sexuality issues (Verge and Cabruja 2017).

Our empirical analysis of the resistance that gender action plans meet at the implementation stage and the strategies deployed by gender equality actors draws on 25 semistructured interviews conducted face-to-face between May 2019 and February 2020 in five universities. We applied a purposive sampling strategy that accounts for significant variance in terms of university type, size, region, year of adoption of the first gender action plan, and creation of equality units (see Table 1). All interviewees were involved in implementation processes or had significant knowledge of universities' equality structures and gender action plans. Our sample -23 women and 2 men - constitutes a mixed group in terms of roles and positional power within the organization: people involved in the equality units, including current and former directors, staff, and consultants; members of universities' equality commissions or networks; representatives of universities' staff; and vice rectors and top managers ${ }^{3}$ of universities' governing teams.

3. The managerial staff included vice rectors, human resource managers, communications managers, and other senior members of the universities' governing teams. 
Table 1. Characteristics of the universities under examination

\begin{tabular}{|c|c|c|c|c|c|}
\hline Name & Size & Type & Region & Equality Plan & Equality Unit \\
\hline Universidad Complutense de Madrid (UCM) & Large $(83,582)$ & Public & Madrid & 1st plan: 2015 & 2004 \\
\hline Universidad del País Vasco (UPV) & Large $(56,721)$ & Public & Basque Country & $\begin{array}{l}\text { 1st plan: } 2010 \\
\text { 3rd plan: } 2019\end{array}$ & 2009 \\
\hline Universidad de Santiago de Compostela (USC) & Medium $(28,826)$ & Public & Galicia & $\begin{array}{l}\text { 1st plan: } 2009 \\
\text { 3rd plan: } 2014\end{array}$ & 2006 \\
\hline Universitat Pompeu Fabra (UPF) & Small $(14,996)$ & Public & Catalonia & $\begin{array}{l}\text { 1st plan: } 2008 \\
\text { 2nd plan: } 2018\end{array}$ & 2017 \\
\hline Universidad Nebrija (UNNE) & Small $(12,196)$ & Private & Madrid & 1st plan: 2017 & Not created yet \\
\hline \multicolumn{6}{|c|}{$\begin{array}{l}\text { Source: Own elaboration based on universities' data (academic year 2018-19 for UPV and 2019-20 for the other cases). University size includes students, faculty, and } \\
\text { administrative staff. }\end{array}$} \\
\hline
\end{tabular}


Interview data were analyzed using thematic content analysis (Nowell et al. 2017). Primary codes identify instances of resistance or counterresistance, while secondary codes capture more detailed aspects of these two thematic clusterings. Following existing research on resistance to gender equality policy implementation (Lombardo and Mergaert 2013; Mergaert and Lombardo 2014; Verge, Ferrer-Fons, and González 2018), we coded the examples of resistance mentioned in the interviews according to type (explicit/implicit, institutional/individual) and form (denial of the need for gender change, refusal to take responsibility, and trivialization of the importance of equality policies). We also coded the actor exerting the resistance, the enabling factors, and the informal rules underlying resistance. The informal rules were identified through a combination of inductive and deductive reasoning, relying particularly on feminist institutionalist and gendered organizational change works (Benschop and Brouns 2003; Mackay, Kenny, and Chappell 2010; Waylen 2014). In the case of feminist counter-resistance strategies, we coded examples according to form (power to/power with) and the participant actor(s). Moreover, we identified the contested informal rules that triggered the counter-action and its enabling factors, following a mixed deductive-inductive process based on feminist institutionalist analyses and theories of feminist agency.

Awareness of the potential gender oversensitivity of our data analysis due to our feminist worldview (van den Brink and Benschop 2012, 76) led to a cross-examination of the coding process by all authors. As feminist women academics, it is important to critically reflect on our positionality within the research process. In most cases, the researcher and interviewee shared feminist values, academic status, and gender identity. This allowed for a productive rapport and an equal power relation to be established, with interviewees generally feeling comfortable and willing to share accounts of resistance and counter-resistance. In other interviews, notably those with some high-ranking managers, there was a clear symbolic and ideological gap between the participant and interviewer that impacted the fluidity of the conversation, particularly where gender equality policies were explicitly resisted, reflecting a direct example of power over. Being aware of these differences, we were careful to pay equal attention to all voices during the empirical analysis.

\section{POWER OVER AND RESISTANCE TO GENDER EQUALITY REFORMS}

As highlighted by one interviewee, "When we work toward changing power relations, stereotypes, norms, value systems that allow the privileges of 
some, [and] getting rid of the obstacles for others, that's when resistances are found" (UNI2.1). Be they institutional and/or individual, implicit or explicit, the resistances encountered are expressions of power over that seek to maintain the status quo and unequal power relations in higher education institutions. They hinder the effective implementation of gender equality policies in nontrivial ways by constraining the capacity of gender equality actors to perform their functions, even delegitimizing their work, and undermining in practice existing legislative gender equality mandates. The most common forms of resistance are the refusal to accept responsibility for acting on gender inequality - sometimes in combination with trivialization, whereby gender equality measures are treated as unimportant - and the denial of the need for gender change.

As summarized in Table 2, these forms of resistance draw on several gendered informal rules, which often stem from societal gender norms, such as gender roles, male entitlement, or prejudice against feminist policy, or build on apparently gender-neutral academic norms that produce gendered effects, such as individual merit or academic freedom. Regarding the enabling factors, refusal to accept responsibility proliferates due to the lack of external and internal supervision and enforcement mechanisms. It is also facilitated by neoliberal tendencies that reinforce the disembodiment of university practices, demanding employees' total availability that is incompatible with care, and that tend to see gender equality as an instrument of marketized benchmarking. The fact that gender change claims are alien to the university hegemonic culture further enables the trivialization of universities' responsibility, leading to the individualization of care as women's problem. For its part, the denial of the need for change is enabled by the very same organizational gendered subculture and hierarchies that institutional change efforts target and by the echoing of conservative and anti-gender stances.

\section{Refusal to Accept Responsibility}

Across our cases, equality unit directors mentioned a lack of institutionalization of the equality structure. The scarcity of personnel and budget allocation reveals informal norms about gender equality not being an institutional priority (UNI2.1, UNI2.3, UNI4.4, UNI5.3). Furthermore, gender equality work is generally undervalued and insufficiently appreciated by the institution. As expressed by one 
Table 2. Forms of resistance, underlying informal rules, and enabling factors

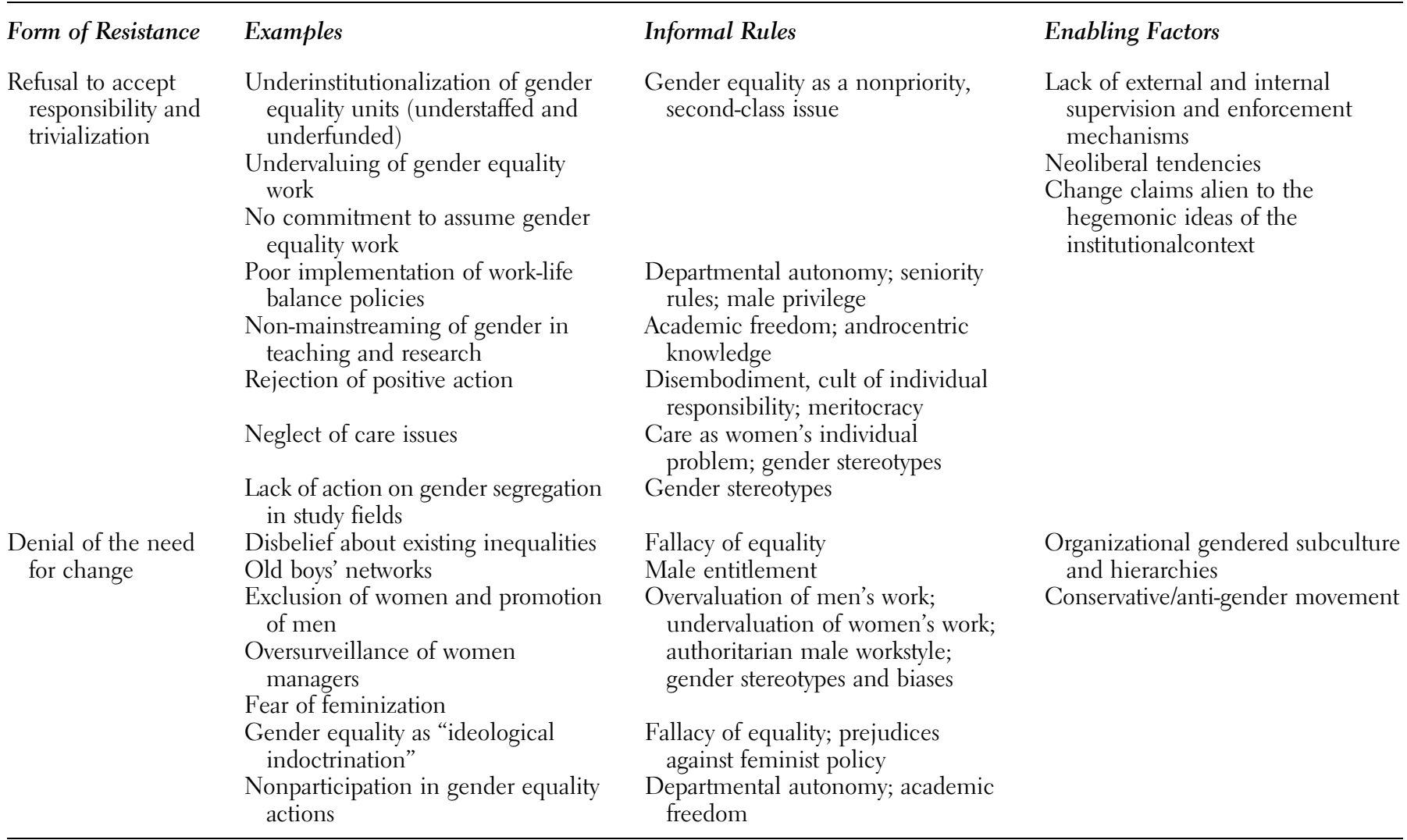


interviewee, "It takes up time and then it's poorly recognized, [there is] an imbalance between the acknowledgement you get and the time that you put into it" (UNI4.3). Indeed, compared with other university management positions, the reduction in teaching hours afforded to those individuals who lead the equality unit tends to be significantly lower. Underfunded, understaffed, and undervalued equality units face the challenge of doing gender mainstreaming work with governing teams that refuse to acknowledge their responsibility and that regard gender inequality as an issue that "women are taking care of" (UNI5.2), which reinforces the assumption that it is the exclusive responsibility of the equality unit to implement the gender action plan. Frequently, governing teams are not even aware of existing policies: "When we [the equality unit] presented the evaluation/monitoring report on the plan, one vice rector was shocked. He asked: 'Are you saying we've done very little!?"' (UNI5.3). This institutional lack of commitment permeates faculties and their departments, ${ }^{4}$ as well as administrative and service units with duties related to the implementation of the university's gender action plan.

A lack of knowledge of the gender equality policies adopted by the institution means that "it's difficult that each area assumes responsibility" (UNI5.4), so implementation often depends on the goodwill of a few individuals (UNI1.4, UNI3.4, UNI4.1). Refusal to accept responsibility can translate into a visible manifestation of power as resistance against positive actions, perceived as inappropriate for the academic context and incompatible with meritocracy, despite being included in countrywide and regional legislation. As a male interviewee stated, "Positive discrimination tells you that, although others are better, I have to positively discriminate in favor of the minority. . I would never do that" (UNI3.2). Refusal to accept responsibility is coupled with trivialization as he "joked" that an ethnic minority, disabled, and gay individual "might not need to read or write in order to get into Harvard."

Institutional nonprioritization is a driving factor of this explicit resistance. Gender equality actors from all cases express a feeling of powerlessness in the face of institutional resistance that undermines formal rules by failing to accept their normative force through nonactions. As an informant stated in relation to the lack of gender balance

4. In the Spanish university system, several departments (teaching and research units) may sit within a faculty (school). 
in governing bodies, "push-back from all sectors" means that "the Equality Law and its promotion of parity was not very helpful [in guaranteeing implementation]" (UNIl.2). The use of soft verbs (e.g., "promote") and emphasis on general principles rather than specific actions, as well an absence of targets and oversight mechanisms within Spain's equality and universities legislation, facilitate this (Verge 2021).

Resistance also affects policies aimed at helping individuals balance work and family life. Discourses around care as a women's issue that "individualize the problem" (UNI2.3) are found across most cases: "If you have children, it's your problem" (UNIl.6). "It's your responsibility, leave us in peace" (UNI2.3). Here, explicit individual resistance, in the forms of refusal to accept responsibility and trivialization, stems from institutional resistance to provide adequate work-life balance policies. Again, gender equality legislation "is there, but it is not put into practice" (UNI1.6). As a result, covering during a colleague's maternity leave is perceived by some "as if they're doing you a favor, but what you're actually doing is claiming, asserting your rights" (UNIl.1), deterring women academics from taking full maternity leaves or from speaking up out of fear (UNI1.4). These attitudes reinforce hierarchical power relations within departments. Similarly, the Spanish employment culture of presentism and long workdays, reinforced by neoliberal trends of employee total availability (La Barbera and Lombardo 2019), prevents the effective provision of flexible teaching timetable measures for faculty with care responsibilities. As stated by one female interviewee, "In principle, you have the right to work-life balance by law. Yet, what happens? They say that if the class schedule doesn't work for you, then you can't teach this course" (UNI2.1).

Informal practices prioritizing academic hierarchy prevail, whereby "those with more seniority can choose [teaching times] first," meaning that "the last person to choose is typically a woman or a parent" (UNIl.6). Senior female professors often perpetuate this informal rule; having been discriminated themselves in the past, they are unwilling to forgo the privilege of choice to help younger female peers with young children (UNI1.3, UNI2.3). Lack of internal and/or external enforcement of work-life balance legislation means the consideration of care responsibilities ends up depending "on the sensibility of each department" (UNI5.5) and "the goodwill of the individuals in charge" (UNI1.4, UNI2.2). In this case, resistance is underpinned by informal norms about gender roles (i.e., perceptions of women as being more oriented toward caregiving than toward professional goals), individual 
responsibility, and a culture of disembodiment (see also Verge, Ferrer-Fons, and González 2018, 97).

Concerning the implementation of equality measures combating horizontal segregation, such as positive actions, resistance as a refusal to accept responsibility is intertwined with trivialization. A female STEM faculty member stated, "I don't think it can be done, and I don't think it should be done. This type of career doesn't get the attention of women . . . women are more inclined to everything related to the social domain, to [careers with] social benefit" (UNI2.2). Although some universities have established mentoring programs for women STEM students, the non-establishment of positive action measures and the lack of gender-targeted promotion of STEM study programs explain the slow pace of feminization. Entrenched gender stereotypes, including among women faculty members, with respect to career choices underpin this resistance.

As for the measures that promote the incorporation of the gender perspective into teaching content, refusal to accept responsibility for their implementation is expressed through non-action. At the individual level, this resistance is grounded in academics' high degree of autonomy, with academic freedom being a key hegemonic idea of the university setting. As argued by one interviewee, "Cultural change is difficult, especially in the university where there is a lot of clearance for people to do what they want. Researchers have authority. . . so they can say: "nope, I don't fancy doing that" (UNI4.1). On the one hand, equality policies "require effort," which might "create extra work" (UNI5.4). On the other hand, resisting actors consider gender equality actions as "having nothing to do with them" (UNI2.3), as not part of their research agenda, and therefore the equality unit "can't tell them what to do" (UNI5.2). Institutional roadblocks reinforce this individual resistance. As one interviewee stated, mainstreaming gender into one's teaching is "not useful for academic career promotion" (UNI5.4). Gender equality criteria are deemed irrelevant, most crucially because universities do not make them compulsory nor do they monitor their effective implementation.

\section{Denial of the Need for Change}

Resistance expressed in the form of denial of the need for change toward gender equality exemplifies how gender structures power relations in 
universities. Organizational gendered culture and hierarchies allow this resistance to endure even when gender action plans have been adopted. One manager stated, "Are there barriers for women? Yes. Do these barriers exist in my institution? Absolutely and radically, no" (UNI3.2). Denial also manifests in the questioning of data around inequality and the false idea that equality has already been achieved. One interviewee noted that when gender data are presented, "people are surprised . . . in some cases, they even deny things like the salary gap. Brutal resistance" (UNI2.3). Another lamented the lack of attendance at gender training sessions for evaluation panel members: "They don't go because no one believes they are sexist, that there are gender biases" (UNI5.4). These less visible manifestations of power over by resistant actors, expressed as denial of the evidence of gender inequality or denial of the problem altogether, can lead to the delegitimization of equality work and institutional inertia (Lombardo and Mergaert 2013, 307).

Actors from privileged groups deny the need for change toward gender equality to maintain the benefits they feel entitled to. Power over operates here through old boy's networks that distribute resources among male members, as exposed by various interviewees: "Well, there are groups of power, controlled by men of a certain, advanced age, and they're not going to let go of what they've got" (UNI4.2), "the "old glories' who haven't wanted, and don't want to change” (UNI4.6). These statements reveal how male homosocial networks keep power within, excluding women while upholding male privilege: "Those with access to power, to decision-making bodies are the most resistant. If it's about sharing or redistributing power, because at that level you can move between people you trust. And if your circles are mostly integrated by men, you know, well, there can be resistances of this type" (UNI4.3).

Similarly, powerful male-dominated or traditionally "masculine" faculties and departments are most resistant to gender equality change. According to one interviewee, "The faculties with the most power medicine, engineering - are fearful of the changes . . . it's also a very sexist field. . . they don't want women" (UNI4.6). Resistance here is underpinned by a sense of entitlement to privileges, serving to undervalue women's status and maintain men's advantage. "Fear of academic feminization" and scholarly devaluation (Morley 2011) also drive some male faculty members to resist equality measures included in the action plan. As a gender equality actor argued, "It's like they're protecting this way of being, thinking and acting. It's like a kind of caste" (UNI4.2). There are clear advantages for privileged groups for doing so: 
"Where there is money, there is power, and normally it's difficult for women to enter" (UNI4.2). Research funding decision-making is a less visible form of power over underpinned by implicit gender biases that overvalue male academics' work, obstructing the achievement of equality objectives. For example, in one department, male principal investigators were granted an average of $€ 300,000$ versus an average of $€ 3,000$ for women principal investigators, despite there being an equal number of men and women leading research projects (UNI2.3).

Resistances that deny the need for gender changes are commonly underpinned by the fallacy of equality. As one interviewee stated, "There are those that are 'in favor' of equality but say that we are already equal, so don't be 'feminazis.' Like 'yes, but let's not exaggerate or go too far"' (UNI4.1). However, this form of resistance has also been recently enabled by anti-gender, conservative movements that convey antifeminist stances, with opposition to gender equality policy founded on right-wing arguments against "extreme feminism" and "ideological indoctrination” (UNI2.2, UNI3.1, UNI4.2, UNI5.2). These explicit manifestations of conservative attitudes among academic staff and students translate into equality units being accused of "doing gender ideology" (UNI2.1).

Individual and institutional resistances that deny the need for change toward gender equality have dramatic consequences for gender equality work. In the absence of both a clear institutional mandate and an assumption of responsibility for equality work across the universities' faculties, departments, or administrative and service units, the authority and credibility of the equality units' director and staff are undermined. This may manifest as personal attacks (Agócs 1997, 53). One interviewee reflected that in certain departments, she is seen as "the freak, the radical feminist. . . the vampire" (UNI5.3). Resistance against gender equality actors stems from the relatively widespread consideration of gender reforms and feminism as indoctrination that has no place in the allegedly objective and neutral university (Verge, Ferrer-Fons, and González 2018, 97).

Prejudices toward feminist policy are also based on ideological beliefs and perceptions of feminism's divisiveness. One male manager claimed that "with equality issues, it's easy to find 'Talibans'. . . a 'Taliban' equality unit is problematic" (UNI3.1). However, resistance is not always so explicit. It may also manifest through inaction regarding the implementation of gender equality policies, revealing underlying prejudices: "There are people who oppose the very existence of equality 
units, to those that work on gender issues. They believe it's unnecessary, a waste of resources. But they don't clearly show their opposition, rather they opt for nonparticipation" (UNI5.3).

At the highest ranks of university management, resisting actors make gender equality actors, especially those in charge of equality units, feel excluded: "Sometimes I enter certain circles of men and no one lets me talk, no one looks at me" (UNI4.2). Gender equality actors express having been subject to oversurveillance and hostility, experiencing "prejudice about women not being able to lead adequately or being too bossy" (UNI4.3). Underlying sexism and gender stereotypes coupled with masculine, authoritarian leadership practices and exclusionary male patronage systems (Alonso, Diz, and Lois 2016) lead to these women being treated as "space invaders" (Puwar 1994), as holding positions they do not legitimately occupy.

\section{SETTING POWER TO AND POWER WITH IN MOTION TO COUNTERACT RESISTANCE}

The power struggle underpinning the implementation of gender reforms in universities also includes dynamics of counter-resistance by gender equality actors with dedicated change agendas who wield individual (power to) and collective agency (power with). As seen in Table 3, utilizing a variety of strategies and forming alliances inside and outside the university, gender equality actors seek to counteract the forces obstructing the implementation process and push for change. At the individual level, strategies that enhance power to include strategically framing gender equality actions within the university's hegemonic discourses around quality and excellence, aligning with social movement campaigns, and reaching out to external actors and institutions through "bridging strategies" to gain visibility and legitimacy and secure third-party enforcement of the actions. These strategies also serve to debunk ideas around the myth of gender inequality. As in other institutional settings, the "embeddedness" (Meyerson and Tompkins 2007, 318) of the lead gender equality actor (the equality unit director) in multiple environments within and outside the institution enhances her capacity to deploy power to, leveraging it from multiple sources and employing an assortment of strategies to raise the profile of gender inequality as an issue and drive accountability.

Collective feminist counter-resistance, power over, also allows for the contestation of norms that consider gender equality a nonpriority or nonlegitimate goal, prompting those who may avoid taking responsibility 
Table 3. Forms of counter-resistance, contested informal rules, and enabling factors

\begin{tabular}{|c|c|c|c|}
\hline $\begin{array}{l}\text { Form of } \\
\text { Counter- } \\
\text { resistance }\end{array}$ & Example & Contested Informal Rules & Enabling Factors \\
\hline \multirow[t]{8}{*}{ Power to } & $\begin{array}{l}\text { Reasserting the equality unit's } \\
\text { positional power }\end{array}$ & $\begin{array}{l}\text { Gender equality as nonpriority, second-class } \\
\text { issue } \\
\text { Prejudices against feminist policy }\end{array}$ & Equality legislation \\
\hline & Strategic framing & $\begin{array}{l}\text { Gender equality as nonpriority, second-class } \\
\text { issue }\end{array}$ & $\begin{array}{l}\text { Relevance of quality assurance, sustainability, } \\
\text { or excellence for universities }\end{array}$ \\
\hline & $\begin{array}{l}\text { Engagement with global } \\
\text { feminist campaigns }\end{array}$ & Fallacy of equality & Strength of the women's movement \\
\hline & $\begin{array}{l}\text { Engagement with other } \\
\text { public or private institutions }\end{array}$ & & $\begin{array}{l}\text { Relevance of knowledge transfer and public } \\
\text { exposure for universities' social impact }\end{array}$ \\
\hline & $\begin{array}{l}\text { Inclusion in high-ranked } \\
\text { decision-making bodies }\end{array}$ & $\begin{array}{l}\text { Gender equality as nonpriority, second-class } \\
\text { issue }\end{array}$ & $\begin{array}{l}\text { Political will of the university's rector; equality } \\
\text { actors' social capital and negotiation skills }\end{array}$ \\
\hline & & Departmental autonomy; academic freedom & \\
\hline & Playing the resignation card & $\begin{array}{l}\text { Equality unit directors as not essential in } \\
\text { university management }\end{array}$ & Equality actors' social capital \\
\hline & $\begin{array}{l}\text { Signing agreements with } \\
\text { other public institutions }\end{array}$ & $\begin{array}{l}\text { Gender equality as nonpriority, second-class } \\
\text { issue }\end{array}$ & $\begin{array}{l}\text { Shared gender equality objectives; } \\
\text { embeddedness of equality actors in external } \\
\text { networks }\end{array}$ \\
\hline
\end{tabular}


Table 3. Continued

\begin{tabular}{|c|c|c|c|}
\hline $\begin{array}{l}\text { Form of } \\
\text { Counter- } \\
\text { resistance }\end{array}$ & Example & Contested Informal Rules & Enabling Factors \\
\hline \multirow[t]{7}{*}{ Power with } & $\begin{array}{l}\text { Rescaling, decentralizing the } \\
\text { equality structure }\end{array}$ & $\begin{array}{l}\text { Gender equality as nonpriority, second-class } \\
\text { issue }\end{array}$ & $\begin{array}{l}\text { Shared progressive, feminist values; equality } \\
\text { actors' social capital; high-level support; } \\
\text { departmentalized organizational structure }\end{array}$ \\
\hline & $\begin{array}{l}\text { Alliances with feminist } \\
\text { academics }\end{array}$ & \multirow{4}{*}{$\begin{array}{l}\text { Androcentric knowledge } \\
\text { Hostile university culture; misogyny, } \\
\text { authoritarian work styles, male entitlement } \\
\text { and privilege) }\end{array}$} & \multirow{2}{*}{$\begin{array}{l}\text { Shared progressivism and feminist values; } \\
\text { informal feminist work; women's } \\
\text { homosociality; equality actors' social capital }\end{array}$} \\
\hline & $\begin{array}{l}\text { Alliances with central services } \\
\text { or individuals in key } \\
\text { positions }\end{array}$ & & \\
\hline & Alliances with students & & $\begin{array}{l}\text { Shared feminist values; strength of the } \\
\text { women's movement }\end{array}$ \\
\hline & $\begin{array}{l}\text { Alliances within } \\
\text { interuniversity forums }\end{array}$ & & $\begin{array}{l}\text { Shared feminist strategies and good practices; } \\
\text { support of mainstream actors }\end{array}$ \\
\hline & \multirow[t]{2}{*}{ Alliances with external actors } & $\begin{array}{l}\text { Gender equality as nonpriority, second-class } \\
\text { issue }\end{array}$ & \multirow[t]{2}{*}{$\begin{array}{l}\text { Shared feminist values, embeddedness of } \\
\text { equality actors in external networks }\end{array}$} \\
\hline & & Androcentric knowledge & \\
\hline
\end{tabular}


for equality work to play more active roles. As more actors become engaged, pressure for change is simultaneously exerted from above and from below, eventually maximizing the chances of containing or overcoming opposition. University equality units may also bolster their positional power and legitimacy, helping to cement their institutionalization through the creation of new scalar equality structures that might include the decentralization of implementation work. Allying with students, feminist or gender-friendly academics, administrative personnel, and high-ranking institutional actors encourages local authentic action and fosters a more favorable climate that may further the implementation of gender action plans. Gender equality actors also turn to "soft spaces" alongside more formal institutional networks to gain support and legitimacy for equality work. Alliances with institutional and civil society actors, the strength of the feminist movement, and strategic framings to legitimize equality, as well as the embeddedness of the principal change actor in feminist networks, are key for supporting the work of equality institutions. These strategies resonate with those identified by the state feminism literature. Ultimately, equality units can be conceived of as women's policy agencies within university settings.

\section{Power To}

Across all our cases, gender equality actors considered the role of the equality units in reclaiming the legal mandates targeting universities to be fundamental: to empower them to act, to fend off accusations of doctrinal ideology, and to convince governing teams of the need for gender change (UNI1.2, UNI2.4, UNI3.4, UNI4.2, UNI5.1). Yet, because legislative mandates on gender equality are insufficient on their own to overcome resistance, equality unit directors in universities have strategically engaged with mainstream discourses to drive implementation forward. They have framed the incorporation of the gender perspective into teaching "as a matter of quality assurance" of the study program (UNI5.3) and aligned with discourses around sustainable development (UNI4.2, UNI5.3). Tapping into higher education institutions' orientation towards excellence in a highly competitive marketplace, they have deployed discourses such as "all the universities are doing it: we can't be left behind” (UNI1.2, also UNI2.4, UNI3.1) and used university performance rankings to compel resistant actors to support specific actions (UNI5.3). 
The strength of street-level women's movement mobilizations in the past few years, ${ }^{5}$ and their increasing media influence has also helped gender equality actors avert resistance and facilitated action, particularly against gender-based violence. Capturing the social zeitgeist, equality units have engaged with \#MeToo and the LGBTI "Safe Space" global campaigns (UNI4.6, UNI5.5), affording an enhanced legitimacy and visibility to equality work and to the unit itself. Likewise, the equality unit director's engagement on an individual level, in external debates or activities as a gender expert/activist, gives her extra legitimacy to deploy "the same discourse within and outside the university," exposing her to less explicit internal resistance (UNI5.3).

Power to can also be afforded to equality units by high-ranking managers (UNI1.2, UNI1.3, UNI5.1) and university rectors (UNI1.5, UNI2.4, UNI5.3). When these actors make explicit commitments to gender equality policy and publicly display their trust in equality actors, status quo actors have a harder time in contesting or subverting actions. For example, "A departmental selection committee said maternity leave points shouldn't be weighted so much... . The Rector called and said "no, this is not optional, you have to apply it" (UNI2.2). Having nonfeminist allies with political weight "carrying your ideas into a forum" can be highly instrumental (UNI3.4). To increase the gender awareness of top decision makers and incentivize commitment, equality actors have organized workshops around gender training sessions (UNI2.3, UNI5.1). These actions are windows of opportunity to mobilize gender-friendly actors to support the implementation of gender equality goals.

Second, integrating the equality unit director in the university's top decision-making bodies empowers her and the equality unit with an enhanced authority vis-à-vis the organizational structure, providing her greater "access to information, knowing what decisions are being made and when, and the people making those decisions" (UNI2.3, also UNI1.1, UNI2.4, UNI5.3). As one interviewee stated, this "above all enables you to know the university from within, something that is absolutely essential to do good gender mainstreaming" (UNI2.4). When sitting on decision-making bodies, equality actors can reinforce links with department directors or vice rectors, who play a key role in instructing their different units and services. Closeness, mutual trust, and friendship

5. The women's movement has staged large-scale street protests against court rulings on sexual violence cases in recent years and organized massive women's strikes in 2018 and 2019 on International Women's Day. 
are social capital that enables gender equality actors to request involvement in the implementation of specific actions (UNI2.4, UNI5.1, UNI5.3).

Accumulating power to takes time; it requires establishing personal relationships and "chemistry" (UNI4.2) with units, services, departments, the managerial team, and the individuals who may be key to ensuring an action's implementation. A second term as an equality unit director is therefore considered essential, allowing this critical actor a deeper perspective on who resists and how, when to seize opportunities, and where alliances are located and how to build new ones, as well as when to act by "surprise," for example, by "playing the resignation card" (UNI5.3). Such acts are utilized to expose institutional resistances and inertias, to denounce the lack of political will, and to demand more resources for the equality unit (UNI1.2, UNI5.3).

Empowerment can also be gained by signing agreements with other public institutions working on gender equality policies, such as regional women's policy agencies that might co-organize workshops, fund research awards for gender-focused dissertations, or secure free access to counseling services for gender-based violence survivors (UNI2.4, UNI5.3). Established around shared equality objectives, these agreements are facilitated by the equality unit director's external connections. Besides enhancing the prominence of the actions and obtaining extra resources to complement equality units' limited budgets and personnel, these collaborations - which require formalization from the rector or vice rector - help diminish resistance as the implementation of these actions becomes subject to third-party scrutiny.

\section{Power With}

The expansion of the equality structures in Spanish universities illustrates the scalar strategy, whereby new spaces or networks are created or existing structures transformed, becoming important sites of feminist counter-resistance to foster policy implementation. Equality units have strengthened or transformed gender equality commissions and networks, either by widening their agenda-setting and accountability roles or by setting up committees of gender experts, feminist activists, and/or genderfriendly actors, with members from across the universities' faculties, departments, and service and administrative units. Enabling factors of this scalar strategy include gender equality actors' individual social capital, high-level support, and an organizational structure in universities 
that allows allies to be "brought in" from all areas. Additional enabling factors are the sharing of progressive and feminist values along with women's homosociality.

These spaces can legitimize the equality unit and its work, and they are "important for creating visibility and to raise consciousness" (UNI2.1). Resistant actors might be more open to gender equality norms and policies when transmitted by peers than by the equality unit (UNI2.2). Outcomes of this gender-conscious rescaling include fostering action in cases of sexual harassment, the gradual use of gender-inclusive language, the increasing adoption of gender-sensitive teaching schedules and number of gender-specific courses, or the organization of roundtables and seminars on key international dates, such as International Women's Day, International Day on Women and Girls in Science, and International Day for the Elimination of Violence against Women (UNI2.2).

Decentralizing the implementation of gender equality policies also helps circumvent institutional resistance or non-action by central university bodies or governing teams. "More liberal," “open," or feminized departments such as sociology or communications (UNI4.2) have acted as "role models," demonstrating to the governing team and the wider university that the breadth of gender equality policy can be furthered. Faculties that remain highly masculinized in Spain, such as STEM, can also play an instrumental role as pioneers, thereby setting "a precedent that gives a lot of legitimacy" (UNI5.3) and paving the way for diffusion across other faculties.

These spaces also provide for mutual recognition and collective empowerment. As one interviewee stated, "In this context of "gender ideology,' it's important to work in alliances that we recognize, and [that] we recognize each other" (UNI2.1). People integrating this formal - yet "soft" - space come together out of a shared progressivism and feminist imperative to transform their workplace. Taking the knowledge and strategies shared here into their daily routines helps participants raise awareness amongst female colleagues "so that they don't feel alone, so they feel increasingly stronger" (UNI5.). It empowers women academics to perform the not always visible work of "local, authentic action" (Meyerson and Scully 1995, 596) that helps foster a more receptive university culture to gender equality policy and constitutes a crucial enabling factor for minimizing resistance (UNI4.2). For example, they can remind their departments about the requirement of parity in recruitment or promotion panels (UNI2.1) or the inclusion of the gender perspective in research seminars (UNI5.2). 
Similarly, equality units can craft informal alliances with central services or individuals within these units for the implementation of policies. Interviewees mentioned that campus management teams have been instrumental in making visible and disseminating anti-harassment protocols and gender action plans. "They allow us to use spaces, set up a "purple point,'6 or put up flyers" (UNI5.3, UNI4.3). Teaching innovation units have also acted as allies, accommodating gender training courses in the annual training programs for the faculty (UNI5.3). Homosociality is another enabling factor, since universities' administrative structures have a highly feminized composition and are often led by women. Deploying this strategy of alliances often requires invisible, behind-the-scenes work (UNI5.4) and some doses of disguise: "The less apparently the policy has to do with the equality unit, the better" (UNI5.2). Gender training sessions are more likely to be well attended and more appealing for reluctant personnel either when the trainer is an external expert (UNI2.4) or when the human resources office includes the session in the annual training program or strategically places it alongside high-level management meetings, thus "indirectly obliging them [to attend]" (UNI5.1).

Students' associations have also acted as allies to gender equality actors, revolting against sexist treatment in the classroom, "putting on the table" the issue of sexual harassment, and giving visibility to anti-harassment policies (UNI2.3, UNI5.2). As one of our participants stated, "The equality unit has always had it clear that our main alliance is with students; the university needs pressure from above as well as from below - it's a 'sandwich' strategy" (UNI5.3). Having the equality unit's office in a visible, on-campus location is considered instrumental for building these alliances (UNI4.2, UNI5.3), and drafting anti-harassment protocols or gender action plans in a participatory, bottom-up approach provides important networking opportunities with students' associations (UNIl.2, UNI2.4, UNI4.2). Nevertheless, allying with students is not always easy. Besides being a collective with a high rotation (UNI5.5), students might still see equality units and feminist academics as institutional actors rather than allies (UNIl.1), which might bring about conflict or tensions.

Evidence on the extent to which the numerous interuniversity forums in Spain have promoted collective agency is mixed. Our interviewees did not report significant power with as a result of participation in the gender

6. A "purple point" ( punto violeta in Spanish) is a designated space in university faculties or university events that provides information and attends to victims of sexist or sexual violence. 
equality working group of the Spanish Universities Rectors' Conference, since it has low visibility and influence capacity. With regard to the countrywide network of public universities' equality units, participants consider it to be of limited instrumental value in terms of concerted lobby but appreciate it as a site for sharing good practices (UNI4.2). Conversely, the working group on gender equality of the Vives University Network, which includes the equality units of Catalan-speaking universities, has crafted several power with strategies aimed at driving the adoption and implementation of gender equality policies, with the full support of the executive secretariat of the network. Jointly, they have produced resources, such as reports on gender bias in academia, a collection of guides to mainstreaming gender in teaching, and guidelines on anti-harassment protocols. The Women and Science Committee of the Inter-University Council of Catalonia has also enabled Catalan universities' equality units to forge alliances with government agencies, achieving the gendering of the quality assurance framework to mainstream gender into curricula (Verge 2021). Thus, in the last two cases, the collaboration of both male and female mainstream actors has granted high-level support to counter-resistance actions.

Lastly, involving external actors in gender equality work can also wield power with. The outsider status of external actors raises the credibility of gender equality work and minimizes resistance from within the organization. When the director of the equality unit is embedded in feminist networks outside the university, she can lead the external consultants in their inquiries and discuss with them how to present the recommendations in a manner that resonates with resistant actors. Engaging in research projects funded by the European Union (see endnote 2) tasked with the formulation, implementation or evaluation of gender equality policies within higher education and research institutions is an example of this strategy (UNI2.4), as well as providing additional sources of high-level legitimation of gender equality actions. Further examples include the hiring of external gender consultants to produce gender audits and reports (UNI5.3) or to provide gender training to the university's staff, both faculty and administrative (UNI4.2).

\section{CONCLUSIONS}

Examining the power struggle that is inherent in the implementation of gender reforms through the lens of a multifaceted feminist concept of 
power has allowed us to capture the dynamic and oppositional nature of this process through a fine-grained analysis of both the factors that enable resistance by dominant actors and counter-resistance by gender equality actors and the informal rules that are being upheld or challenged, respectively. Our conceptualization of explicit and implicit resistance connects with Lukes's (2005) (in)visible manifestations of power over, while we have built on Allen's (1998) work for conceptualizing power as capacity for feminist individual and collective counter-resistance. In this respect, the analytical framework developed in this article enriches feminist institutionalist and policy implementation theories as it takes into account that domination and feminist empowerment are codependent and dynamic processes, with specific enabling factors in a given institutional context.

While this analytical framework can be applied to any policy domain, we have focused on higher education to document the various forms of resistance that thwart the effective implementation of gender equality policies in nontrivial ways. The resistances identified (refusal to take responsibility, often in conjunction with trivialization of gender equality policies, and denial of the need for gender change) are expressions of power over that operate to maintain male privilege and to undermine women's work and roles in academic settings. At the same time, paying attention to feminist counter-resistance deployed individually (power to) or collectively (power with) by actors committed to gendering universities has allowed us to shed light on the fact that political opportunities do not just "hang in there"; rather, new openings can be created (Chappell 2000; Verge 2021). In line with existing institutionalist analyses, we have shown that, while overnight transformation may not be a realistic expectation, gender change can be produced through the cumulative steps of feminist actors. In this way, in Benschop and Verloo's (2006, 31) words, gender equality actors in university settings "can start from a slightly improved position every time."

Future research of distinct national contexts, including specific legislative frameworks and university characteristics, may provide different enabling factors for dominant actors to resist gender equality policies and shape feminist actors' agency and capacity in different ways. Thus, further comparative analyses of national and university contexts would contribute to deepening the understanding of the feminist politics of policy implementation in universities. Not only is gender equality in higher education a global priority, but many of the barriers to gender equality traverse national boundaries (Ahmed 2012; Morley 2011), 
including the hierarchical structure and the gendered or apparently gender-neutral informal rules that structure universities' gender regime. Capturing gender power struggles in higher education institutions by mapping resistance and counter-resistance is all the more important in times of rising global opposition to gender equality and gender studies.

Rebecca Tildesley is a PhD Candidate in Political Science at Universidad Complutense de Madrid: rtildesl@ucm.es; Emanuela Lombardo is Associate Professor of Political Science at Universidad Complutense de Madrid: elombard@ucm.es; Tània Verge is Full Professor of Politics and Gender at Universitat Pompeu Fabra: tania.verge@upf.edu

\section{REFERENCES}

Agócs, Carol. 1997. "Institutionalized Resistance to Organizational Change: Denial, Inaction and Repression." Journal of Business Ethics 16: 917-31.

Ahmed, Sara. 2012. On Being Included: Racism and Diversity in Institutional Life. Durham, NC: Duke University Press.

Allen, Amy. 1998. "Rethinking Power." Hypatia 13 (1): 21-40.

Allmendinger, Phil, and Graham Haughton. 2009. "Soft Spaces, Fuzzy Boundaries, and Meta-Governance: The New Spatial Planning in the Thames Gateway." Environment and Planning A 41 (3): 617-33.

Alonso, Alba, Isabel Diz, and Marta Lois. 2016. "Is Gender Mainstreaming Helping Women Scientists? Evidences from Research Policies in Spain.” Investigaciones Feministas 7 (2): 273-91.

Bardach, Eugene. 1977. The Implementation Game. Cambridge, MA: MIT Press.

Bendl, Regine, Mary Ann Danowitz, and Angelika Schmidt. 2014. "Recalibrating Management: Feminist Activism to Achieve Equality in an Evolving University." British Journal of Management 25 (2): 320-34.

Benschop, Yvonne, and Margo Brouns. 2003. "Crumbling Ivory Towers: Academic Organizing and its Gender Effects." Gender, Work \& Organization 10 (2): 194-212.

Benschop, Yvonne, and Mieke Verloo. 2006. "Sisyphus' Sisters: Can Gender Mainstreaming Escape the Genderedness of Organizations?" Journal of Gender Studies 15 (1): 19-33.

Brenner, Neil. 2001. "The Limits to Scale? Methodological Reflections on Scalar Structuration." Progress in Human Geography 25 (4): 591-614.

Castaño, Cecilia, Susana Vázquez-Cupeiro, and José Luis Martínez-Cantos. 2019. "Gendered Management in Spanish Universities: Functional Segregation among Vice-Rectors." Gender and Education 31 (8): 966-85.

Celis, Karen, and Joni Lovenduski. 2018. "Power Struggles: Gender Equality in Political Representation." European Journal of Politics and Gender 1 (1-2): 149-66.

Chappell, Louise. 2006. "Comparing Political Institutions: Revealing the Gendered 'Logic of Appropriateness.” Politics \& Gender 2 (2): 223-35.

Chappell, Louise, and Fiona Mackay. 2017. "What's in a Name? Mapping the Terrain of Informal Institutions and Gender Politics." In Gender and Informal Institutions, ed. Georgina Waylen. London: Rowman \& Littlefield International, 23-44. 
2020. "Feminist Critical Friends: Dilemmas of Feminist Engagement with Governance and Gender Reform Agendas." European Journal of Politics and Gender. Published online July 10. https://doi.org/10.1332/251510820X15922354996155.

Chappell, Louise, and Georgina Waylen. 2013. "Gender and the Hidden Life of Institutions." Public Administration 91 (3): 599-615.

Childs, Sarah, and Mona Lena Krook. 2009. "Analyzing Women's Substantive Representation: From Critical Mass to Critical Actors." Government and Opposition 44 (2): 125-45.

Elizondo, Arantxa, Ainhoa Novo, and María Silvestre. 2010. Igualdad de mujeres y hombres en las universidades españolas [Equality of women and men in Spanish universities]. Madrid: Instituto de la Mujer.

Engeli, Isabelle, and Amy Mazur. 2018. "Taking Implementation Seriously in Assessing Success: The Politics of Gender Equality Policy." European Journal of Politics and Gender 1 (1-2): 111-29.

Eschle, Catherine, and Bice Maiguashca. 2018. "Theorising Feminist Organising In and Against Neoliberalism: Beyond Co-optation and Resistance?" European Journal of Politics and Gender 1 (1-2): 223-39.

Eyben, Rosalind. 2010. "Subversively Accommodating: Feminist Bureaucrats and Gender Mainstreaming." IDS Bulletin 41 (2): 54-61.

Hart, Jeni. 2008. "Mobilization among Women Academics: The Interplay between Feminism and Professionalization." NWSA Journal 20 (1): 184-208.

Holli, Anne Maria. 2008. "Feminist Triangles: A Conceptual Analysis." Representation 44 (2): 169-85.

La Barbera, MariaCaterina, and Emanuela Lombardo. 2019. “Towards Equal Sharing of Care? Judicial Implementation of EU Equal Employment and Work-Life Balance Policies in Spain." Policy \& Society 38 (4): 626-42.

Lombardo, Emanuela, and Petra Meier. 2009. "Power and Gender: Policy Frames on Gender Inequality in Politics in the Netherlands and Spain." Journal of Women, Politics \& Policy 30 (4): 357-80.

Lombardo, Emanuela, and Lut Mergaert. 2013. "Gender Mainstreaming and Resistance to Gender Training: A Framework for Studying Implementation.” NORA: Nordic Journal of Feminist and Gender Research 21 (4): 296-311.

Lowndes, Vivien. 2020. "How are Political Institutions Gendered." Political Studies 68 (3): 543-64.

Lukes, Steven. 2005. Power: A Radical View. 2nd ed. Basingstoke: Palgrave Macmillan.

Mackay, Fiona. 2020. "Dilemmas of an Academic Feminist as Manager in the Neoliberal Academy: Negotiating Institutional Authority, Oppositional Knowledge and Change." Political Studies Review 19 (1): 75-95.

Mackay, Fiona, Meryl Kenny, and Louise Chappell. 2010. "New Institutionalism Through a Gender Lens: Towards a Feminist Institutionalism?” International Political Science Review 31 (5): 573-88.

MacKinnon, Danny. 2010. "Reconstructing Scale: Towards a New Scalar Politics." Progress in Human Geography 35 (1): 21-36.

Mergaert, Lut, and Emanuela Lombardo. 2014. "Resistance to Implementing Gender Mainstreaming in EU Research Policy." European Integration Online Papers 18 (1): $1-21$.

Meyerson, Debra, and Maureen Scully. 1995. "Tempered Radicalism and the Politics of Ambivalence and Change." Organization Science 6 (5): 585-600.

Meyerson, Debra, and Megan Tompkins. 2007. "Tempered Radicals as Institutional Change Agents: The Case of Advancing Gender Equity at the University of Michigan." Harvard Journal of Law and Gender 30 (2): 303-22. 
Monroe, Kristen, Saba Ozyurt, Tmured Wrigley, and Amy Alexander. 2008. "Gender Equality in Academia: Bad News from the Trenches and Some Possible Solutions." Perspectives on Politics 6 (2): 215-32.

Morley, Louise. 2007. "The Gendered Implications of Quality Assurance and Audit.” In Challenges and Negotiations for Women in Higher Education, eds. Pamela Cotterill, Sue Jackson, and Gayle Letherby. Dordrecht: Springer, 53-63.

—. 2011. "Misogyny Posing as Measurement: Disrupting the Feminisation Crisis Discourse." Contemporary Social Science: Journal of the Academy of Social Sciences 6 (2): 223-35.

Nowell, Lorelli S., Jill M. Norris, Deborah E. White, and Nancy J. Moules. 2017. "Thematic Analysis: Striving to Meet the Trustworthiness Criteria." International Journal of Qualitative Methods 16 (1): 1-13.

Pastor, Inma, Ana Acosta, Teresa Torres Coronas, and Marta Calvo Merino. 2020. "Los planes de igualdad en las universidades españolas. Situación actual y retos de futuro" [Gender equality plans in Spanish universities. Current situation and future challenges]. Educación XX1 23 (1): 147-72.

Pastor, Inma, Paloma Pontón, Ángel Belzunegui, and Ana Acosta. 2015. "Gender Policies in Spanish Universities: From Regulation to Equality Plans.” In Women's Voices in Management, eds. Helena D. Syna and Carmen-Eugenia Costea. London: Palgrave Macmillan, 34-51.

Puwar, Nirmal. 2004. Space Invaders. Oxford: Berg.

Puy, Ana, ed. 2018. Científicas en Cifras 2017. Estadísticas e indicadores de la (des) igualdad de género en la formación y profesión científica [Figures about Women Scientists 2017. Statistics and indicators about gender (in)equality in training and scientific professions]. Madrid: Ministerio de Ciencia e Innovación.

Roggeband, Conny. 2018. "The Good, The Bad, and The Ugly. Making Sense of Opposition to Feminisms from a Social-Movement Perspective." In Varieties of Opposition to Gender Equality in Europe, ed. Mieke Verloo. London: Routledge, 19-37.

Valian, Virginia. 2004. "Beyond Gender Schemas: Improving the Advancement of Women in Academia." NWSA Journal 16 (1): 207-20.

van den Brink, Marieke, and Yvonne Benschop. 2012. "Slaying the Seven-Headed Dragon: The Quest for Gender Change in Academia." Gender, Work and Organization 19 (1): 71-92.

Verge, Tània. 2021. "Gender Equality Policy and Universities: Feminist Strategic Alliances to Re-gender the Curriculum." Journal of Women, Politics \& Policy.https://doi.org/l0. 1080/1554477X.2021.1904763

Verge, Tània, and Maria de la Fuente. 2014. "Playing with Different Cards: Party Politics, Gender Quotas and Women's Empowerment." International Political Science Review 35 (1): 67-79.

Verge, Tània, Mariona Ferrer-Fons, and Maria José González. 2018. "Resistance to Mainstreaming Gender into the Higher Education Curriculum." European Journal of Women's Studies 25 (1): 86-101.

Verge, Tània, and Emanuela Lombardo. 2021. "The Contentious Politics of Policy Failure: The Case of Corporate Board Gender Quotas in Spain." Public Policy and Administration 36 (2): 232-51.

Verge, Tània, and Teresa Cabruja Ubach. 2017. "La perspectiva de gènere a la docència i a la recerca a les universitats de la Xarxa Vives: Situació actual i reptes de futur" [Integrating a gender perspective in teaching and research in universities of the Xarxa Vives: Current situation and future challenges]. Barcelona: Xarxa Vives d'Universitats.

Verloo, Mieke. 2018. Varieties of Opposition to Gender Equality in Europe. London: Routledge. 
Waylen, Georgina. 2014. "Informal Institutions, Institutional Change, and Gender Equality." Political Research Quarterly 67 (1): 212-23.

Weick, Karl. 1984. "Small Wins: Redefining the Scale of Social Problems." American Psychologist 39 (1): 40-49.

Woodward, Alison. 2003. "Building Velvet Triangles: Gender and Informal Governance." In Informal Governance in the European Union, eds. Thomas Christiansen and Simona Piattoni. Cheltenham: Edward Elgar, 76-93. 